\title{
The 12-Month Incidence and Predictors of PHQ-9- Screened Depressive Symptoms in Chinese Primary Care Patients
}

Weng-Yee Chin, MBBS, FRACGP1,2

Eric Yuk Fai Wan, MSc, BSc ${ }^{1,2}$

Edmond Pui Hang Choi, BNurs, $M P b i l^{3}$

Kit Tsui Yan Chan, MSc, BSSc',2

Cindy Lo Kuen Lam, MBBS, MD, MCGP, FRCGP, FHKAM ${ }^{1,2}$

'Department of Family Medicine \& Primary Care, The University of Hong Kong, Hong Kong,

${ }^{2}$ Ap Lei Chau Clinic, Ap Lei Chau, Hong Kong

${ }^{3}$ School of Nursing, The University of Hong Kong, Hong Kong SAR, China
Conflicts of interest: authors report none.

\section{CORRESPONDING AUTHOR}

Weng-Yee Chin, MBBS (UWA), FRACGP Department of Family Medicine \& Primary Care

The University of Hong Kong

3/F Ap Lei Chau Clinic

161 Main St

Ap Lei Chau, Hong Kong

chinwy@hku.hk

\begin{abstract}
PURPOSE Evidence regarding the onset of depressive symptoms in primary care is rarely available but can help inform policy development, service planning, and clinical decision making. The objective of this study was to estimate the 12-month cumulative incidence and predictors of a positive screen for depressive symptoms on the 9-item Patient Health Questionnare-9 (PHQ-9) among primary care patients with no history of physician-diagnosed depression.
\end{abstract}

METHODS We monitored a cohort of 2,929 adult primary care patients with no past history of physician-diagnosed depression and with baseline PHQ-9 scores of 9 or lower by telephone interview at 3, 6 , and 12 months. A generalized linear mixed effects Poisson Model was used to explore factors associated with the incidence of PHQ-positive symptoms.

RESULTS The cumulative incidence of positive screening on the PHQ-9 over 12 months was $5.23 \%$ (95\% Cl, 3.83\%-6.64\%). Positive predictors included being female, coming from a lower-income household, being a smoker, having at least 2 comorbidities, having a family history of depression, and having consulted a physician at least twice in the past 4 weeks. Consulting a physician with qualifications in both family medicine and psychological medicine was a negative predictor.

CONCLUSIONS The cumulative incidence of PHQ-9-screened depressive symptoms in this study population was higher than those reported for depressive disorders in earlier systematic reviews. Groups who may warrant greater treatment attention include women, patients with multimorbidity, smokers, patients with recent high rates of medical consultations, and those who are from lower-income households or who have a family history of depression. Greater physician training may have a protective effect.

Ann Fam Med 2016;14:47-53. doi: 10.1370/afm.1854.

\section{INTRODUCTION}

$\mathrm{D}$ epressive disorders are a leading cause of illness burden and a public health priority. ${ }^{1}$ Primary care is the entry point for most people requiring health services, and in many countries, depressive disorders are managed in primary care. The prevalence of depressive disorders in primary care has been estimated to range between $10 \%$ and $20 \%{ }^{2}$ Despite this prevalence, very few cohort studies have examined the incidence of depressive disorders in this setting. Some have assessed incidence using physicians' case reports or retrospective reviews of medical records for case identification ${ }^{3,4}{ }_{;}$however, systematic reviews have shown that roughly $50 \%$ of depressive disorders are missed in primary care ${ }^{5}$ i hence, such estimates may exclude patients who have not been identified as having depression by a physician. One way to overcome this issue is by using patient self-reported symptoms for case finding. Use of depression screening instruments for case finding helps to overcome errors in case detection due to lifetime recall bias or to misidentification by clinicians; however, a shortcoming of this approach is that these instruments are self-reported and 
subjective. They are also limited by their sensitivity and specificity for diagnosing depressive disorders.

In the 2010 Global Burden of Disease Study, the worldwide incidence of depressive disorders was estimated using pooled data from various population-based studies, including those using symptom scale survey instruments. The estimated global incidence of depressive disorders in that year ranged from $2.7 \%$ for males to $3.4 \%$ for females; however, most of the data came from western settings, with a notable lack of data from Asia. ${ }^{6}$

Hong Kong is a Special Administrative Region of the People's Republic of China. Approximately 95\% of the 7 million people living in the region are of Chinese descent. Hong Kong has a pluralistic health care system wherein patients can receive primary care services from physicians in the pay-for-service private sector as well as from government-subsidized General Outpatient Clinics of the Hong Kong Hospital Authority. Furthermore, many patients use both conventional western and traditional Chinese medicine services for primary care.

To help inform health policy formation and promote evidence-based clinical decision making, it is essential to have information that encompasses the natural course and risk factors for onset of a disease. ${ }^{7}$ For disorders that often have a chronic or relapsing and remitting course, estimates of the rate of development of new cases can help inform policy makers regarding future service needs. ${ }^{8}$ The aim of this study was to estimate the 12-month cumulative incidence of and risk factors associated with screening positive for depressive symptoms on the 9-item Patient Health Questionnare-9 (PHQ-9) among primary care patients in Hong Kong. Findings from this study will contribute to the global epidemiologic knowledge on depressive disorders in nonwestern settings.

\section{METHODS}

\section{Study Design}

We conducted a 12 -month prospective cohort study as part of a larger epidemiologic study examining the natural history of depressive disorders in Hong Kong's primary care setting. Baseline recruitment of patients took place between October 2010 and January 2012. Longitudinal data were collected between October 2010 and January 2013. The study protocol and findings from the cross-sectional study on prevalence and physician rates of depression identification have been previously published. ${ }^{9,10}$

\section{Setting and Patients}

We invited 59 primary care physicians working in clinics located territory-wide across Hong Kong to collaborate as part of a primary care practice-based research network. Physicians were identified using the mailing list of the Hong Kong College of Family Physicians and worked in a variety of practice settings, including private settings (solo practice, group practice, outpatient departments of private hospitals), government-funded General Outpatient Clinics, and nonprofit, nongovernmental organizations, reflecting the diversity of settings in which primary care is delivered in Hong Kong.

All consecutive, eligible patients seeking care from a study physician on a single randomly selected day each month over a 12 -month recruitment period were approached in the waiting room. We used a 12 -month baseline recruitment period to account for seasonal variability and to enhance the representation of the case load. Patients were excluded if they were aged younger than 18 years; did not speak or understand English, Cantonese, or Mandarin, had cognitive or communication difficulties; had previously been recruited to the study; or did not consult the physician.

Questionnaires containing the PHQ-9, the Center for Epidemiologic Studies-Depression Scale (CES-D 20), the Medical Outcomes Study Short-Form version 2 (SF-12v2), and items on health service use, past medical history, help-seeking behaviors, and sociodemographic characteristics (available in English or Chinese) were distributed to patients in the waiting room and were self-completed. To enhance the completion rate, a research assistant was on site to administer the questionnaire to those with poor literacy or eyesight, and to answer any queries. Physicians (who were blinded to the PHQ-9 screening scores) were asked to document the patient's reason for seeking care, to express their opinion on whether the patient had depression (yes/ no), and to outline their management if they identified the patient as having depression.

Patients who completed the baseline questionnaire were invited to participate in the longitudinal follow-up. Those who consented by providing their name and contact details were included. Follow-up data were collected using a questionnaire that contained the PHQ-9, the CES-D 20, the SF-12v2, and items on recent health service use, and administered by telephone interview at 12,26 , and 52 weeks by trained research staff.

Patients in the longitudinal sample who had negative PHQ-9 screening scores at baseline (score $\leq 9$ ), who were not identified as having depression by the study physician at baseline, and who reported having no past history of physician-diagnosed depression formed the cohort population to examine incidence of PHQ-9-screened depressive symptoms.

\section{Study Instruments}

The PHQ-9 is a 9-item questionnaire used to screen for, monitor, diagnose, and measure the severity of 
depressive symptoms. ${ }^{11}$ It scores each of the 9 diagnostic criteria of the Diagnostic and Statistical Manual of Mental Disorders, 4th Edition (DSM-IV) for depression from 0 (not at all) to 3 (nearly every day) over the previous 2 weeks. ${ }^{12}$ The Chinese version of the PHQ-9 has been validated in Hong Kong. ${ }^{13}$ Using a cut-off score of greater than 9, the PHQ-9 was found to have a sensitivity of $80 \%$ and a specificity of $92 \%$ for diagnosing major depression. ${ }^{13}$ For this study, a PHQ-9 score of 9 or less (PHQ negative) at baseline was used for eligibility and a score of greater than 9 (PHQ positive) was used to identify incident-depressive symptoms.

Questions on patient sociodemographics, health habits, chronic disease comorbidity (including hypertension, diabetes mellitus, heart disease, stroke, asthma, emphysema, chronic bronchitis or other chronic lung diseases, arthritis or other chronic rheumatism, and chronic pain), and self-reported western and Chinese medicine service use in the past month were included in the baseline questionnaire for use as independent variables. Physicians' demographic and practice characteristics were also included as independent variables. Service delivery differs between the public and private sectors. Government clinics mainly cater to patients needing chronic disease management, the elderly, and those who cannot afford private care; private practice caters more to patients seeking care for acute and episodic illnesses. Specialist training of physicians occurs in the public sector, and physicians in this sector are more likely to be training for or have qualifications in family medicine; however, workload is high and consultation times are generally much shorter (average 5.5 minutes) than in the private sector. ${ }^{14}$

Baseline detection status of depression by the study physician was collected using a case-record form completed at the time of the index consultation. Identification of depression (defined as a patient with clinically important depressive symptoms) was unassisted and physicians were blinded to the PHQ-9 scores.

\section{Statistical Analysis}

We estimated the 12-month cumulative incidence of PHQ-9-positive depressive symptoms in patients who screened PHQ-9 negative at baseline and who reported no past history of depression with a $95 \%$ confidence interval, taking into account clustering by practice. Differences in baseline characteristics between patients with and without onset of PHQ-9positive symptoms over a 12 -month period were tested using independent $t$ tests for continuous variables or $\chi^{2}$ tests for categorical variables. We used a generalized linear mixed effects Poisson model with robust error variance that also took into account the withinpractice correlation to explore predictors of incidence. The intraclass correlation coefficient (ICC) was used to estimate how much variation in the incidence of depressive symptoms existed between patients and between physician practices. We used the pseudo $\mathrm{R}^{2}$ according to the McFadden approach to evaluate the goodness of fit of the model.

All statistical analyses were performed using Stata version 13.0 (StataCorp LP). All significance tests were 2-tailed, and those with a $P$ value less than .05 were considered statistically significant.

\section{Ethics Approvals}

This study was approved by the institutional review board of the University of Hong Kong/Hospital Authority Hong Kong West Cluster, the Research Committee of Evangel Hospital, the Research Com-

Figure 1. Patient inclusion in the study and in regression analyses.

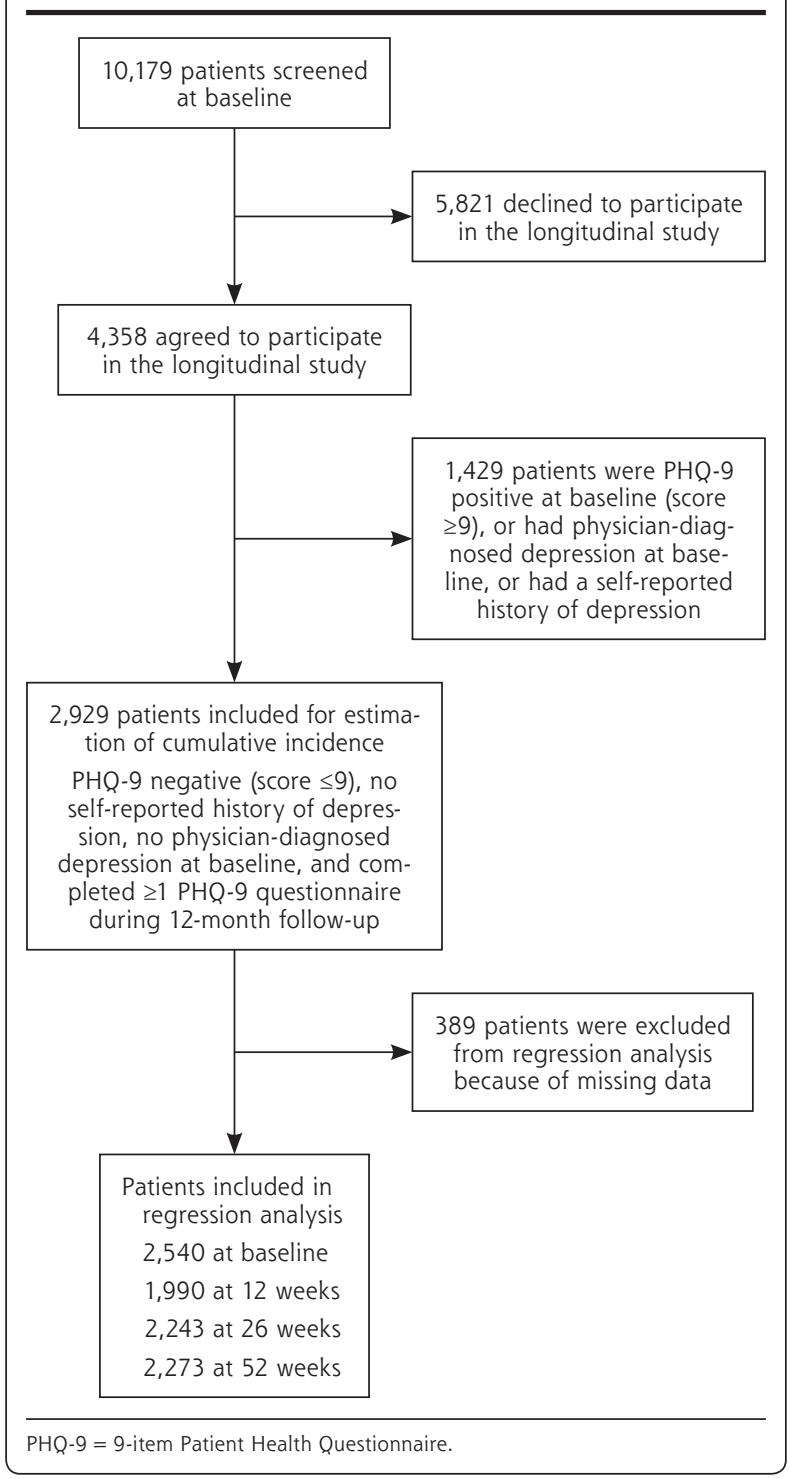


mittee of Hong Kong Sanatorium and Hospital, the Research Committee of Matilda International Hospital, the Research Ethics Committee for Hong Kong Hospital Authority Kowloon East Cluster and Kowloon Central Cluster, and the Joint Chinese University of Hong Kong and Hong Kong Hospital Authority New Territories East Cluster Clinical Ethics Review Committee. All participants provided signed informed consent.

\section{RESULTS}

\section{Response Rate}

Overall, 10,179 patients completed the baseline questionnaire (Figure 1). Of these, 4,358 patients consented to longitudinal follow-up, including 3,819 patients who were PHQnegative; 890 were excluded because they had a past history of depression, had depression detected by the study physician at baseline, or did not have at least 1 follow-up PHQ-9 score. As a result, a total of 2,929 patients were included for the calculation of cumulative incidence. Their baseline characteristics are shown in Table 1.

\section{Incidence of PHQ-9-Screened Depressive Symptoms}

Over 12 months, 147 patients screened PHQ-9 positive on at least 1 follow-up interview. After adjustment for clustering by practice, the 12-month cumulative incidence for depressive symptoms was $5.23 \%$ (95\% CI, 3.83\%-6.64\%). In subgroup analysis by sex, the 12 -month cumulative incidence in women and men was $6.30 \%$ (95\% CI, 4.23\%-8.38\%) and $4.15 \%$ (95\% CI, 2.22\%-6.08\%), respectively.

\section{Predictors of Incidence}

After excluding 389 patients because of missing data, a total of 2,540 patients were included in the regression analysis. Of this group, 1,990 patients, 2,243 patients,
Table 1. Baseline Characteristics of Study Patients, Overall and by PHQ-9 Screening Status Over the 12-Month Follow-up

\begin{tabular}{|c|c|c|c|c|}
\hline \multirow[b]{2}{*}{ Characteristic } & \multirow[b]{2}{*}{$\begin{array}{c}\text { Total } \\
(\mathrm{N}=2,929)\end{array}$} & \multicolumn{2}{|c|}{$\begin{array}{c}\text { PHQ-9 Screening Status } \\
\text { Over } 12 \text { Months }\end{array}$} & \multirow[b]{2}{*}{$\begin{array}{c}P \\
\text { Value }\end{array}$} \\
\hline & & $\begin{array}{c}\text { Negative } \\
(n=2,782)\end{array}$ & $\begin{array}{l}\text { Positive } \\
\text { ( } n=147)\end{array}$ & \\
\hline \multicolumn{5}{|l|}{ Patient factors } \\
\hline Sex, \% & & & & .058 \\
\hline Male & 44.3 & 44.7 & 36.7 & \\
\hline Female & 55.7 & 55.3 & 63.3 & \\
\hline Age, mean (SD), y & $\begin{array}{l}49.3 \\
(7.0)\end{array}$ & $\begin{array}{c}49.2 \\
(16.9)\end{array}$ & $\begin{array}{l}51.7 \\
(18.2)\end{array}$ & .08 \\
\hline Ethnicity, \% & & & & .68 \\
\hline Chinese & 98.2 & 98.2 & 98.6 & \\
\hline Non-Chinese & 1.8 & 1.8 & 1.4 & \\
\hline Marital status, \% & & & & .03 \\
\hline Married & 65.4 & 65.9 & 57.1 & \\
\hline $\begin{array}{l}\text { All others (single, separated, } \\
\text { divorced, widowed) }\end{array}$ & 34.6 & 34.1 & 42.9 & \\
\hline Household monthly income, \% & & & & .003 \\
\hline $\begin{array}{l}\text { Moderate or higher income } \\
\quad(>\mathrm{HK} \$ 30,000)\end{array}$ & 41.5 & 42.2 & 29.1 & \\
\hline Lower income $(\leq \mathrm{HK} \$ 30,000)$ & 58.5 & 57.8 & 70.9 & \\
\hline Education level, \% & & & & .01 \\
\hline $\begin{array}{l}\text { Secondary or tertiary } \\
\text { education }\end{array}$ & 76.6 & 77.1 & 68.0 & \\
\hline $\begin{array}{l}\text { No formal or primary } \\
\text { education }\end{array}$ & 23.4 & 22.9 & 32.0 & \\
\hline Employment status, \% & & & & .33 \\
\hline Employed & 65.0 & 65.4 & 56.8 & \\
\hline Unemployed & 1.2 & 1.2 & 1.4 & \\
\hline Retired & 20.9 & 20.6 & 26.7 & \\
\hline Homemaker & 10.5 & 10.4 & 12.3 & \\
\hline Student & 2.4 & 2.4 & 2.7 & \\
\hline Smoking status, $\%$ & & & & .08 \\
\hline Nonsmoker & 88.2 & 88.4 & 83.7 & \\
\hline Smoker & 11.8 & 11.6 & 16.3 & \\
\hline Drinking status, \% & & & & .94 \\
\hline Nondrinker & 87.6 & 87.5 & 87.8 & \\
\hline Drinker & 12.4 & 12.5 & 12.2 & \\
\hline Exercise status, \% & & & & .61 \\
\hline Exercise & 73.7 & 73.6 & 75.5 & \\
\hline No exercise & 26.3 & 26.4 & 24.5 & \\
\hline Number of comorbidities, $\%$ & & & & $<.001$ \\
\hline 0 & 48.0 & 48.6 & 37.4 & \\
\hline 1 & 27.4 & 27.6 & 24.5 & \\
\hline$\geq 2$ & 24.6 & 23.9 & 38.1 & \\
\hline & & & & continues \\
\hline
\end{tabular}


Table 1. Baseline Characteristics of Study Patients, Overall and by PHQ-9 Screening Status Over the 12-Month Follow-up (continued)

\begin{tabular}{|c|c|c|c|c|}
\hline \multirow[b]{2}{*}{ Characteristic } & \multirow[b]{2}{*}{$\begin{array}{c}\text { Total } \\
(\mathrm{N}=2,929)\end{array}$} & \multicolumn{2}{|c|}{$\begin{array}{c}\text { PHQ-9 Screening Status } \\
\text { Over } 12 \text { Months }\end{array}$} & \multirow[b]{2}{*}{$\begin{array}{c}P \\
\text { Value }\end{array}$} \\
\hline & & $\begin{array}{l}\text { Negative } \\
(n=2,782)\end{array}$ & $\begin{array}{l}\text { Positive } \\
\text { (n=147) }\end{array}$ & \\
\hline \multicolumn{5}{|l|}{ Patient factors (continued) } \\
\hline $\begin{array}{l}\text { Family history of mental } \\
\text { illness, } \%\end{array}$ & & & & .03 \\
\hline Yes & 90.5 & 90.8 & 85.3 & \\
\hline No & 9.5 & 9.2 & 14.7 & \\
\hline $\begin{array}{l}\text { Number of visits to a western } \\
\text { physician in past } 4 \text { weeks, } \%\end{array}$ & & & & .02 \\
\hline 0 & 51.6 & 51.5 & 53.5 & \\
\hline $1-2$ & 38.9 & 39.3 & 31.3 & \\
\hline$\geq 3$ & 9.5 & 9.2 & 15.3 & \\
\hline $\begin{array}{l}\text { Number of visits to a tradi- } \\
\text { tional Chinese medicine prac- } \\
\text { titioner in past } 4 \text { weeks, } \%\end{array}$ & & & & .80 \\
\hline 0 & 85.5 & 85.5 & 84.7 & \\
\hline$\geq 1$ & 14.5 & 14.5 & 15.3 & \\
\hline District of residence, $\%$ & & & & .61 \\
\hline Hong Kong & 43.3 & 43.1 & 46.6 & \\
\hline Kowloon & 23.7 & 23.7 & 24.0 & \\
\hline New Territories & 33.0 & 33.2 & 29.5 & \\
\hline \multicolumn{5}{|l|}{ Physician factors } \\
\hline Sex, \% & & & & .64 \\
\hline Male & 72.4 & 72.5 & 70.7 & \\
\hline Female & 27.6 & 27.5 & 29.3 & \\
\hline Age, mean (SD), y & $44.8(11.8)$ & $\ldots$ & $\ldots$ & $\ldots$ \\
\hline District of practice, $\%$ & & & & .44 \\
\hline Hong Kong & 47.9 & 47.7 & 51.7 & \\
\hline Kowloon & 30.3 & 30.3 & 30.6 & \\
\hline New Territories & 21.8 & 22.0 & 17.7 & \\
\hline Related training, \% & & & & .07 \\
\hline $\begin{array}{l}\text { Vocational training in family } \\
\text { medicine only }\end{array}$ & 48.8 & 48.4 & 55.8 & \\
\hline $\begin{array}{l}\text { Diploma in psychological } \\
\text { medicine only }\end{array}$ & 18.3 & 18.4 & 16.3 & \\
\hline Both & 7.8 & 8.0 & 2.7 & \\
\hline Neither & 25.2 & 25.2 & 25.2 & \\
\hline Practice setting, \% & & & & .004 \\
\hline Public & 29.0 & 28.5 & 39.5 & \\
\hline Private & 71.0 & 71.5 & 60.5 & \\
\hline
\end{tabular}

\section{DISCUSSION}

The cumulative incidence of PHQ-9-screened depressive symptoms in our study $(5.23 \%)$ was higher than the pooled annual incidence of depressive disorders estimated in the Global Burden of Disease Study 2010 study of $3.0 \%$. A wide range of incidence estimations have been reported in various studies ${ }_{i}$ however, methodologic differences in population sampling and case definition make direct comparisons difficult. In the 2010 study, data were derived from community-based samples, who are likely to be healthier and to have lower levels of morbidity than in patient populations. ${ }^{6}$ Furthermore, we used the PHQ-9 to screen for depressive symptoms, which is only a surrogate measure for depressive disorders. As other causes of low mood (such as a reaction to life events or bereavement) can also cause a person to screen positive, incidence estimates for screened depressive symptoms are likely to be higher than those for depressive disorders. In studies examining incidence in primary care populations, estimates have ranged from 6 to 25 per 1,000 patients in Europe and the United Kingdom. ${ }^{3,4}$ In the PREDICT study (Prospective Cohort Study of Unemployment and Clinical Depression in Europe and Chile) conducted in 6 European countries and Chile, the overall cumulative 12-month incidence of DSM-IV major depression in the European population was $7.7 \%$ (United Kingdom, $8.8 \%$; Spain, $15.1 \%$; Slovenia, $4.2 \%$; Portugal, $8.5 \%$; the Netherlands, 5.4\%; and Estonia, 5.9\%). ${ }^{15} \mathrm{~A}$ German study that followed an older adult (aged older than 65 years) primary care cohort using a depression screening tool estimated the incidence of screened depression to be 42.7 per 1,000 patients. ${ }^{16}$

Cross-cultural studies indicate that women are more likely to develop depression than men. ${ }^{17}$ In our study, we found the incidence of depressive symptoms was greater in women $(6.30 \%$ in women vs $4.15 \%$ in men). 
Table 2. Characteristics Associated With Incident Depressive Symptoms in Chinese Primary Care Patients (Fixed Effects)

\begin{tabular}{|c|c|}
\hline Characteristic & $\begin{array}{c}\text { Incidence } \\
\text { Rate Ratio }(95 \% \mathrm{Cl})\end{array}$ \\
\hline \multicolumn{2}{|l|}{ Patient factors ( 2,540 patients) } \\
\hline Female (vs male) & $1.58^{\mathrm{a}}(1.05-2.37)$ \\
\hline Age, in years & $0.99(0.97-1.01)$ \\
\hline Non-Chinese (vs Chinese) & $0.67(0.09-5.17)$ \\
\hline All other marital statuses (vs married) & $1.45(0.89-2.37)$ \\
\hline $\begin{array}{l}\text { Lower income, } \leq \mathrm{HK} \$ 30,000 \text { (vs middle or higher } \\
\text { income, }>\mathrm{HK} \$ 30,000 \text { ) }\end{array}$ & $1.56^{\mathrm{a}}(1.10-2.21)$ \\
\hline $\begin{array}{l}\text { No formal or only primary education (vs secondary } \\
\text { or tertiary education) }\end{array}$ & $1.24(0.81-1.88)$ \\
\hline \multicolumn{2}{|l|}{ Employment status (vs employed) } \\
\hline Unemployed & $0.84(0.18-3.85)$ \\
\hline Retired & $1.24(0.79-1.94)$ \\
\hline Homemaker & $0.70(0.41-1.20)$ \\
\hline Student & $1.54(0.50-4.80)$ \\
\hline Smoker (vs nonsmoker) & $1.73^{\mathrm{a}}(1.04-2.88)$ \\
\hline Drinker (vs nondrinker) & $1.22(0.79-1.90)$ \\
\hline No exercise (vs exercise) & $1.08(0.80-1.45)$ \\
\hline \multicolumn{2}{|l|}{ Comorbidities (vs 0 ) } \\
\hline 1 & $1.16(0.64-2.10)$ \\
\hline$\geq 2$ & $1.92^{\mathrm{a}}(1.18-3.13)$ \\
\hline Family history of mental illness (vs none) & $2.02^{\mathrm{a}}(1.35-3.04)$ \\
\hline \multicolumn{2}{|l|}{ Visits to a western physician in past 4 weeks (vs 0 ) } \\
\hline $1-2$ & $0.79(0.51-1.23)$ \\
\hline$\geq 3$ & $1.90^{\mathrm{a}}(1.18-3.07)$ \\
\hline $\begin{array}{l}\text { Visits to a traditional Chinese medicine practitioner } \\
\text { in past } 4 \text { weeks, any (vs none) }\end{array}$ & $1.04(0.53-2.01)$ \\
\hline \multicolumn{2}{|l|}{ District of residence (vs Hong Kong) } \\
\hline Kowloon & $1.14(0.59-2.20)$ \\
\hline New Territories & $1.17(0.61-2.27)$ \\
\hline \multicolumn{2}{|l|}{ Physician factors (59 physicians) } \\
\hline Female (vs male) & $0.69(0.38-1.26)$ \\
\hline Age, in years & $1.00(0.97-1.03)$ \\
\hline \multicolumn{2}{|l|}{ Practice district (vs Hong Kong) } \\
\hline Kowloon & $0.85(0.44-1.64)$ \\
\hline New Territories & $0.69(0.33-1.43)$ \\
\hline \multicolumn{2}{|l|}{ Related training (vs neither) } \\
\hline Family medicine training & $0.91(0.49-1.72)$ \\
\hline Diploma in psychological medicine & $1.04(0.59-1.82)$ \\
\hline Both & $0.28^{\mathrm{a}}(0.09-0.89)$ \\
\hline Private setting (vs public) & $0.56(0.30-1.07)$ \\
\hline \multicolumn{2}{|l|}{ Time } \\
\hline Time, in weeks & $1.02^{\mathrm{a}}(1.02-1.03)$ \\
\hline
\end{tabular}

Primary care is the entry point to the medical system. It is therefore important that primary care physicians are aware of who may be at highest risk for developing depressive disorders so that they can implement targeted interventions. One strategy is that high-risk patients could be flagged for waiting room screening, with a subsequent clinical assessment performed by an experienced clinician in those who screen positive. A thorough clinical assessment of those who are identified by screening should be performed to prevent overdiagnosis and overtreatment of patients who do not have a depressive disorder. Also, patients identified by screening need to be assessed for suicidality or atypical features that may require referral to specialist mental health services. In patients with multiple comorbidities, empowerment strategies such as health education or counseling may be useful to help reduce disease complications and enable patients to cope better with their complex biopsychosocial problems.

We found only a single protective factor for incidence: having an index consultation with a primary care physician who was trained both in family medicine and in psychological medicine. In Hong Kong, there are no statutory postgraduate requirements to practice in the private sector, and any registered physician can be a primary care physician in private practice. Reflecting this situation, there was a broad range of training backgrounds among the 59 physicians who participated in this study: 44 had fellowship qualifications (or equivalent) in general practice or family medicine, 1 had done a fellowship in surgery, 1 had done a fellowship in emergency medicine, and the remaining physicians had no postgraduate specialty qualifications. Fourteen of the study physicians held a postgraduate diploma in psychological medicine or the equivalent. In terms of policy recommendations, it appears that adequate training of the medical workforce needs to be a prior-

Other risk factors for increased incidence were similar to those previously reported in the literature, namely, lower household income $\mathrm{e}^{15,18,19}$ and family history of depression. ${ }^{15,20}$ In addition, we also found that being a smoker, having multiple comorbidities, and having seen a western physician more than twice in past 4 weeks were also associated with increased incidence. ity to enhance the quality of care of mental health service delivery in primary care. Although we cannot prove causality, it seems that physicians who are trained in delivering patient-centered care and who also have adequate skills in mental health may be able to help decrease the burden of depressive disorders by reducing the onset of symptoms. 


\section{Table 3. Model Performance in Predicting Incident Depressive Symptoms in Chinese Primary Care Patients}

\begin{tabular}{ll}
\hline Measure & Value \\
\hline Error variance & \\
$\quad$ Intercept, patient, variance (SE) & $1.46(0.89-2.41)$ \\
Intercept, physician, variance (SE) & $0.05(0.002-1.199)$ \\
Goodness of fit & \\
Pseudo R² (McFadden), \% & 18.3 \\
Patient ICC, \% & 33.4 \\
Physician ICC, \% & 4.9 \\
\hline
\end{tabular}

$\mathrm{ICC}=$ intraclass correlation coefficient; $\mathrm{SE}=$ standard error.

Note: 389 patients were excluded from the analysis because of missing values.

This study had several limitations. Our cohort was self-selected, which leads to a risk of self-selection bias. Case finding was based on the PHQ-9, which is a subjective self-reported symptom scale instrument, and was not confirmed by a clinical diagnostic interview, which would be the gold standard for the diagnosis of depressive disorders. The sensitivity and specificity of the PHQ-9 for diagnosing depressive disorders needs to be taken into consideration if scores are used as a surrogate measure for estimating the incidence of these disorders.

In conclusion, we found the 12-month cumulative incidence of PHQ-9-screened depressive symptoms in Chinese primary care was $5.23 \%$. Primary care patients who are female, have multiple comorbidities, smoke, have a lower household income, have a family history of depression, and consult the primary care physician frequently deserve more treatment attention because they have a higher incidence of depressive symptoms. Policies to enhance the training requirements of primary care physicians may help reduce the burden of depressive disorders in Hong Kong.

To read or post commentaries in response to this article, see it online at http://www.annfammed.org/content/14/1/47.

Key words: mental health; depression; primary care; Chinese; screening; practice-based research

Submitted March 25, 2015; submitted, revised, July 22, 2015; accepted August 7, 2015.

Funding support: This work was supported by the Hong Kong Food and Health Bureau's Commissioned Research on Mental Health Policy and Service grant Reference No. SMH-27.

Previous presentation: Who Gets Diagnosed With Depression in Hong Kong's Primary Care and What Happens to Them Over a Year? Presented at NAPCRG's Annual Meeting, 2014, NAPCRG Annual Meeting Distinguished Papers (http://www.annfammed.org/content/12/6/585.full).

\section{References}

1. Ferrari AJ, Charlson FJ, Norman RE, et al. Burden of depressive disorders by country, sex, age, and year: findings from the Global Burden of Disease study 2010. PLoS Med. 2013;10(11):e1001547.

2. Mitchell AJ, Vaze A, Rao S. Clinical diagnosis of depression in primary care: a meta-analysis. Lancet. 2009;374(9690):609-619.

3. Boffin N, Bossuyt N, Declercq T, Vanthomme K, Van Casteren V. Incidence, patient characteristics and treatment initiated for GP-diagnosed depression in general practice: results of a 1-year nationwide surveillance study. Fam Pract. 2012;29(6):678-687.

4. Rait G, Walters K, Griffin M, Buszewicz M, Petersen I, Nazareth I. Recent trends in the incidence of recorded depression in primary care. Br J Psychiatry. 2009;195(6):520-524.

5. Saver BG, Van-Nguyen V, Keppel G, Doescher MP. A qualitative study of depression in primary care: missed opportunities for diagnosis and education. J Am Board Fam Med. 2007;20(1):28-35.

6. Ferrari AJ, Somerville AJ, Baxter AJ, et al. Global variation in the prevalence and incidence of major depressive disorder: a systematic review of the epidemiological literature. Psychol Med. 2013;43(3): 471-481.

7. van Weel C, van Weel-Baumgarten E, Mold J. The importance of longitudinal studies in family medicine: experiences of two practicebased research networks. J Am Board Fam Med. 2006;19(1):69-74.

8. Evans J. Disease incidence. J Comm Eye Health. 1997;10(24):60-62.

9. Chin WY, Lam CL, Wong SY, et al. The epidemiology and natural history of depressive disorders in Hong Kong's primary care. BMC Fam Pract. 2011;12(1):129.

10. Chin WY, Chan KT, Lam CL, et al. Detection and management of depression in adult primary care patients in Hong Kong: a cross-sectional survey conducted by a primary care practice-based research network. BMC Fam Pract. 2014;15(1):30.

11. Spitzer RL, Kroenke K, Williams JBW. Validation and utility of a selfreport version of PRIME-MD: the PHQ primary care study. Primary Care Evaluation of Mental Disorders. Patient Health Questionnaire. JAMA. 1999;282(18):1737-1744.

12. Kroenke K, Spitzer RL, Williams JB. The PHQ-9: validity of a brief depression severity measure. J Gen Intern Med. 2001;16(9):606-613.

13. Yu X, Tam WWW, Wong PTK, Lam TH, Stewart SM. The Patient Health Questionnaire-9 for measuring depressive symptoms among the general population in Hong Kong. Compr Psychiatry. 2012;53(1): 95-102.

14. Mercer SW, Fung CS, Chan FW, Wong FY, Wong SY, Murphy D. The Chinese-version of the CARE measure reliably differentiates between doctors in primary care: a cross-sectional study in Hong Kong. BMC Fam Pract. 2011;12(1):43.

15. King $M$, Walker $C$, Levy $G$, et al. Development and validation of an international risk prediction algorithm for episodes of major depression in general practice attendees: the PredictD study. Arch Gen Psychiatry. 2008;65(12):1368-1376.

16. Weyerer $\mathrm{S}$, Eifflaender-Gorfer $\mathrm{S}$, Wiese $\mathrm{B}$, et al. Incidence and predictors of depression in non-demented primary care attenders aged 75 years and older: results from a 3-year follow-up study. Age Ageing. 2013;42(2):173-180.

17. Piccinelli M, Wilkinson G. Gender differences in depression. Critical review. BrJ Psychiatry. 2000;177(6):486-492.

18. Weich S, Lewis G. Poverty, unemployment, and common mental disorders: population based cohort study. BMJ. 1998;317(7151):115-119.

19. Lorant V, Croux C, Weich S, Deliège D, Mackenbach J, Ansseau M. Depression and socio-economic risk factors: 7-year longitudinal population study. Br J Psychiatry. 2007;190(4):293-298.

20. Angst J, Gamma A, Endrass J. Risk factors for the bipolar and depression spectra. Acta Psychiatr Scand Suppl. 2003;108(418):15-19. 